http://jmscr.igmpublication.org/home/ ISSN (e)-2347-176x ISSN (p) 2455-0450 crossref DOI: https://dx.doi.org/10.18535/jmscr/v9i2.34

\title{
Intraoperative raised airway pressures-Back to basics
}

\author{
Author
}

\section{Dr Shivi}

MBBS, DNB Anaesthesia, Senior Resident, Department of Anaesthesia, SMS Medical College and Hospital

\begin{abstract}
Endotracheal tube kinking, though uncommon during surgery, can lead to serious ventilatory challenges. Kinking of endotracheal tube can present as raised airway pressures which is to be differentiated from other causes. We report a case of kinking of intraoral part of endotracheal tube in a neurosurgical procedure.

Keywords: Airway pressures, Endotracheal tube, Kinking, Intraoral.
\end{abstract}

\section{Introduction}

Modern day anaesthesia practice allows anaesthetist to monitor airway pressures. Intraoperative raised airway pressures can be because of several reasons. Kinking of breathing circuits or endotracheal tube (ETT) is one of the cause for increased airway pressures. Diagnosing kinking of ETT can be challenging if it is of intraoral portion and delayed rectification of problem can lead to deleterious outcomes. We hereby present a case of kinking of intraoral portion of ETT and consequences thereafter.

\section{Case}

A 52 year old female with post traumatic right sided extradural haemorrhage was taken for emergency hematoma evacuation. Induction was done with intravenousinjection fentanyl 100 micrograms and injection thiopentone 250 milligrams. Neuromuscular blockade achieved with injection vecuronium5.5 milligrams and trachea intubated with a 7.5 millimetre Internal Diameter cuffed orotracheal tube. Tube placement was confirmed with the presence of end tidal carbon dioxide tracings. The tube was moved from the right angle of mouth and fixed on the left angle. The air entry was verified, by auscultation, to be bilaterally equal. The lungs were mechanically ventilated (volume-controlled mode with tidal volume $420 \mathrm{~mL}$ and respiratory rate 16 breaths/min) using Drager Primus Workstation. The airway pressure just after intubation was 16 $\mathrm{cmH}_{2} \mathrm{O}$. For surgery, head of the patient was rotated to left side with some flexion of the neck. About half an hour after the start of surgery, airway pressures started rising and reached 44 $\mathrm{cmH}_{2} \mathrm{O}$. The end tidal carbon dioxide tracings showed upward slope. Ventilator mode was changed to hand ventilation. The bag was found to be very tight to squeeze. Any kinking in ventilator circuit and extra oral part of endotracheal tube was ruled out and HME filter changed to rule out any obstruction. On auscultation bilateral air entry was reduced. Severe bronchospasm was suspected and managed with increasing the depth of anaesthesia, intravenous steroids and endotracheal puffs of inhalers. All this was in vein as there was no improvement in peak pressures and bag 
compliance. We asked the surgeons to hold the surgery and laryngoscopy was done. The intraoral portion of endotracheal portion was found to be kinked against the hard palate. The tube was changed and air entry checked. Bilateral air entry was present with good bag compliance and peak pressures of $15 \mathrm{~cm} \mathrm{H}_{2} \mathrm{O}$ on volume control mode.

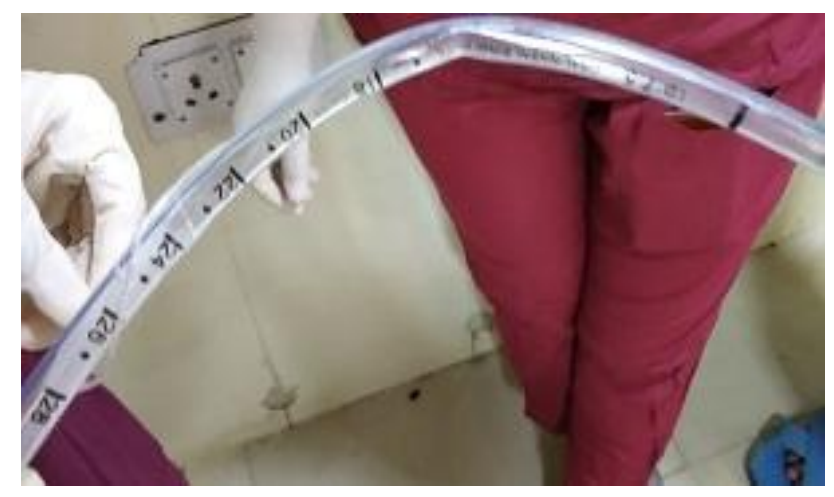

\section{Discussion}

High intraoperative airway pressures can be because of airway obstruction, reduced compliance, increased resistance, oxygen flush activation during the inspiratory phase, a punctured ventilator bellows, occlusion or obstruction of the expiratory limb of the breathing system, scavenger malfunction, or the patient coughing or straining ${ }^{(1,2)}$. Kinking of an ETT, extraoral or intraoral, can cause airway obstruction. ETT kinking during anaesthesia and surgery is generally uncommon ${ }^{(3)}$, but may occur more commonly if the position of the head and neck over bends the ETT ${ }^{(4,5)}$. Flexometallic ETTs are prefered in cases (e.g., neurosurgery or maxillo-oral surgery) where strong bending forces are expected or if the ETT is not easily accessible during surgery. Due to non-availability of flexomettalic tube we used normal ETT tube for intubation.

If the ETT's temperature is increased to $36^{\circ} \mathrm{C}$, the tube softens and kinking occurs at astonishingly low angles. The kinking typically occurs where the cuff line exits, $18 \mathrm{~cm}$ from the tube's tip, a spot usually hidden in the oral cavity ${ }^{(6)}$. In our case also the kink might resulted from overbending of the softened tube in the oral cavity due to oral temperature and neck flexion.
Early identification of cause of airway obstruction is necessary as airway obstruction leads to defective ventilation. Carbon dioxide accumulation due to compromised ventilation can lead to raised intracranial pressures (ICP).

Prolonged raised ICP in neurosurgical cases can lead to grave outcomes. In our case, oxygen saturation of the patient remained $\geq 98 \%$ throughout the incidence, which was a false reassurance of everything being alright.

Several case reports mention that an ETT kinking can mimic bronchospasm ${ }^{(7,8)}$ as both conditions present with inability to ventilate, raised airway pressures and decreased breath sounds in severe bronchospasm.

\section{Conclusion}

In the surgeries involving head and neck flexometallic endotracheal tubes should be used. The anaesthetist present should be vigilant for all parameters as some can be falsely reassuring while others may be showing some serious problem. Kinking of intraoral part of endotracheal tube should always be kept in mind as a cause and should be looked upon for early as timely change of ETT can reverse changes occurred due to defective ventilation. The same is of more importance particularly in neurosurgical cases.

\section{References}

1. Myerson KR, Ilsley AH, Runciman WB. An evaluation of ventilator monitoring alarms. Anaesth Intens Care 1986; 14:174-185

2. Anonymous. Heat/moisture exchange humidifiers. Technol Anesth 1991; $11: 5$

3. Szekely SM, Webb RK, Williamson JA, Russell WJ. The Australian Incident Monitoring Study. Problems related to the endotracheal tube: an analysis of 2000 incident reports. Anaesth Intensive Care 1993; 21:611-16.

4. Inada T, Shingu K, Yamanouchi Y, Katoh A. Delayed kinking of the tracheal tube 
during neck flexion in a paediatric neurosurgical patient. PaediatrAnaesth 1998; 8:364.

5. Korn S, Schubert A, Barnett G. Endotracheal tube obstruction during stereotactic craniotomy. J Neurosurg Anesthesiol 1993; 5:272-5.

6. Hübler, Matthias, MD, DEAA; Petrasch, Frank Intraoperative Kinking of Polyvinyl Endotracheal Tubes, Anesthesia \& Analgesia: December 2006 - Volume 103 Issue 6 - p 1601-1602

7. Park C, Kim H, Yum K. Acute obstruction of an endotracheal tube: a case report. Anesth Prog 2004; 51:62-64.

8. Lee YW, Lee TS, Chan KC, Sun WZ; Lu $\mathrm{CW}$. Intratracheal kinking of endotracheal tube. Can J Anesth 2003; 50:311-312. 